\title{
Fire in the Wildland-Urban Interface: Selecting and Maintaining Firewise Plants for Landscaping ${ }^{1}$
}

\author{
J. Douglas Doran, Cotton K. Randall, Alan J. Long ${ }^{2}$
}

\section{Introduction}

One of the major issues in the southern wildland-urban interface is the loss of homes to wildfire. For homeowners who live in an area with a medium to high risk of wildfire, this document provides useful information for protecting your property (see University of Florida/IFAS publication FOR 71 "Landscaping in Florida with Fire in Mind" to determine your wildfire risk, http://edis.ifas.ufl.edu/FR076; new wildfire risk assessment guidelines for homeowners in the southern USA will be released in the summer of 2004 by the University of Florida/IFAS). While fire control agencies play an important role in fire prevention and the protection of homes, there are actions that individual homeowners can take to reduce the vulnerability of their home to wildfire. Creating an area of defensible space is one of the most important. Defensible space is defined as an area of modified vegetation between natural areas (e.g., woodlands) and homes that breaks up the continuity of plants and allows firefighters to protect the home or, in absence of firefighters, allows the home to better survive on its own. Recommendations for defensible space suggest maintaining an area extending at least 30 feet outward from a house with plants that are low in flammability (referred to as firewise plants).

Selecting landscape plants based on their flammability can be challenging for homeowners and landscapers, as few existing plant guides list firewise plants or rank plants by their flammability. However, by considering several key plant characteristics that are known to influence flammability, homeowners can make informed decisions about which plants to select when creating an area of defensible space, or how to modify existing plants to prevent the spread of wildfire. The movement of a wildfire is controlled primarily by the flammability of the plants that are present and how those plants are arranged, both vertically and horizontally. This extension publication outlines plant characteristics that have the greatest effect on flammability, as discussed at three levels: plant parts (primarily leaves), whole plants, and groups of plants. Selecting firewise plants can reduce wildfire risk, but during drought conditions,

1. This document is Circular 1445, one of the series Fire in the Wildland-Urban Interface of the School of Forest Resources and Conservation, Florida Cooperative Extension Service, Institute of Food and Agricultural Sciences, University of Florida. First published: March 2004. The development of this fact sheet was funded by the National Fire Plan through the Southern Center for Wildland-Urban Interface Research and Information, Southern Research Station, USDA Forest Service.

2. J. Douglas Doran is a graduate student, Cotton K. Randall is the Wildland-Urban Interface Fire Project Coordinator, and Alan J. Long is Associate Professor, School of Forest Resources \& Conservation, Institute of Food and Agricultural Sciences, University of Florida, Gainesville, 32611. 
most plants will burn if exposed to enough heat, regardless of their flammability.

\section{What Plant Parts 'Fuel' the Fire?}

Plants are the primary fuel during wildfires, and both living and dead plant material will burn. When comparing the flammability of different plants, one should first consider the leaves and small branches, which are lightweight fuels that ignite easily and burn rapidly. These lightweight fuels, or light fuels, facilitate the spread of an advancing fire and carry the fire to heavier fuels, such as larger branches or even houses. Leaves from different plant species ignite and burn at different rates and intensities depending on chemical and structural characteristics. The most important characteristics of light fuels that influence their flammability are:

- The amount of water in a leaf, or its moisture content. The moisture content of leaves varies significantly by season, as well as by local weather and site conditions, such as air humidity and soil moisture, but differences also exist between plant species growing under the same conditions. Plants that have thick, succulent leaves, such as cacti, aloe, and century plants, generally maintain high leaf moisture content, even during droughts, and thus have a low flammability. Most living leaves are at least $50 \%$ water by weight. When exposed to heat or a flame, a leaf will not catch fire until most of its water is lost (primarily through evaporation). Therefore, leaves with the highest moisture content generally take the longest to ignite. Dead leaves are much drier than living leaves.

- The size and shape of leaves. Small, needle-like leaves, like those on pines and cedars, are generally more flammable than wider, flat leaves, such as those on maples, oaks, and hickories. The broad leaves of palms (called fronds) are exceptions to this rule, as they tend to have a relatively high flammability. Leaf thickness is important because thick leaves have more plant tissue (and often more water) relative to the area of exposed surface than thin leaves. Due to these physical properties, when most thin leaves are exposed to fire, they ignite faster than thick leaves. When dead leaves drop from a tree, their shape can affect whether they get caught in shrubs below and thereby increase the flammability of those shrubs. For example, the fact that pine needles are attached at the base increases their likelihood of getting caught on small branches as they fall, and the flammability of shrubs and small trees increases as needles accumulate (Figure 1).

- The presence of oils, resins (e.g., tree sap), waxes, or other chemicals in leaves or branches. Certain chemicals can increase the flammability of a plant. When landscaping around homes in high wildfire hazard areas, homeowners should limit the use of plants with high amounts of resins or oils in their leaves. Leaves containing significant amounts of these chemicals will often emit an odor when crushed.

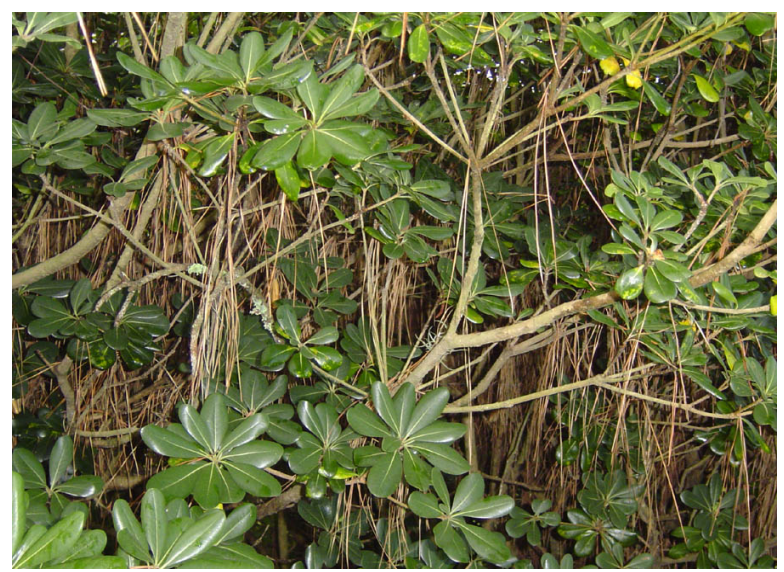

Figure 1. Dead needles, falling from taller pines, can accumulate or drape on branches of smaller trees and shrubs, like the pittosporum in this picture. The dry, dead needles dramatically increase the flammability of the shrub and vegetation around it. Credits: Anna L. Behm, University of Florida

\section{Whole-Plant Flammability}

The overall flammability of a plant is dependent on the relative flammability of its leaves and branches, and how they are arranged. For example, flames might spread quicker and more easily through a shrub with layers of leaves and small branches than they would through a loosely branched shrub with few leaves. Shrubs and trees differ in their flammability based on several key characteristics.

- Branching patterns are important because they influence the distribution and amount of leaves. Plants with open and loose branching and sparse leaves generally have a low flammability. A few examples of plants with relatively open, loose 
branching include ornamental plum trees, crape myrtle, and some azaleas.

- Deciduous vs. evergreen. Shrubs and trees that lose their leaves in the fall are referred to as deciduous, and those that retain living leaves throughout the year are called evergreen. In the southern United States, some common deciduous species include hickories, red and white oaks, and maples. Many common evergreen species have needle-like leaves, such as cedars, pines, and hemlocks; however, some broad-leaved plants are also evergreen, such as live oaks, hollies, and magnolias. Deciduous plants are usually less flammable than evergreens for several reasons. Living deciduous leaves tend to have a higher moisture content than evergreen leaves. In addition, deciduous plants do not readily ignite during winter because they have no leaves to burn. However, as described in the section on leaves, the leaf size and shape is an important plant characteristic to consider, and leaves vary within each group (deciduous and evergreen). For example, magnolias and cedars are two evergreens that have very different leaves, and they vary in their flammability, with the cedar being more flammable due to its small, needle-like leaves.

\section{- The retention of dead leaves and branches} can increase a plants flammability due to the low moisture content of dead materials (Figure 2). As forest trees grow taller, their lower branches that receive little sunlight often die. However, the dead branches may remain attached for a period of time and contribute to the flammability of the entire tree. Some trees, called self-pruners, lose their lower, dead branches on their own as they grow. Self-pruning can lower a plant's flammability by creating greater vertical separation between the ground and the part of the tree containing leaves (Figure 3). Manual removal of branches up to 10 feet from the ground will reduce the fire hazard of mature trees that do not self-prune.

\section{- Planting "the right plant in the right} place" is important in landscaping, and it can influence plant flammability. When selecting landscape plants, consider their light, water, and soil requirements (http://hort.ufl.edu/fyn/right-plant-right-place.htm).

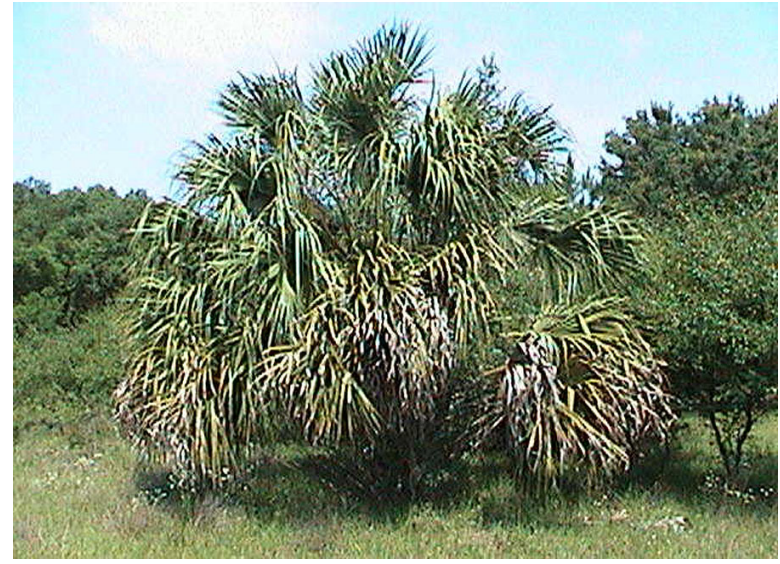

Figure 2.b Credits: J. Douglas Doran, University of Florida

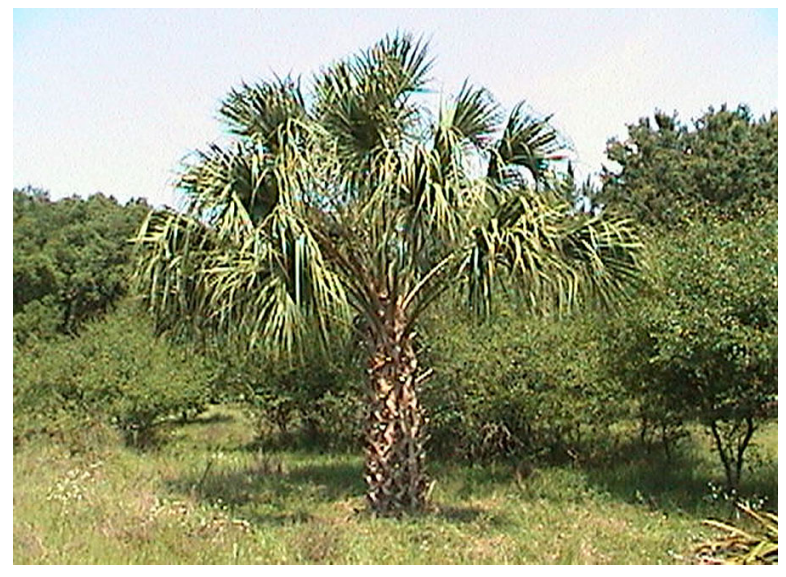

Figure 2.c Credits: J. Douglas Doran, University of Florida

Figure 2. The dead or dying fronds on this cabbage palm (b) increase its overall flammability and create a fire hazard when in close proximity to a house. By removing the dead fronds (c), the hazard can be reduced.

If you are a homeowner, contact your county extension agent or local nursery for assistance in selecting appropriate plants for the range of conditions in your yard. Plants that are not well suited for the local environment often require more resources, such as water and fertilizer, and may become stressed or diseased. Unhealthy plants have a higher percentage of dead leaves and branches, which significantly increase their flammability.

\section{Plant Arrangement within the Landscaped Area (and Beyond)}

Similar to individual plants, the flammability of groups of landscape plants is influenced significantly by the vertical and horizontal arrangement of fuels. In many cases, the arrangement of groups of plants around a house is more important in determining 


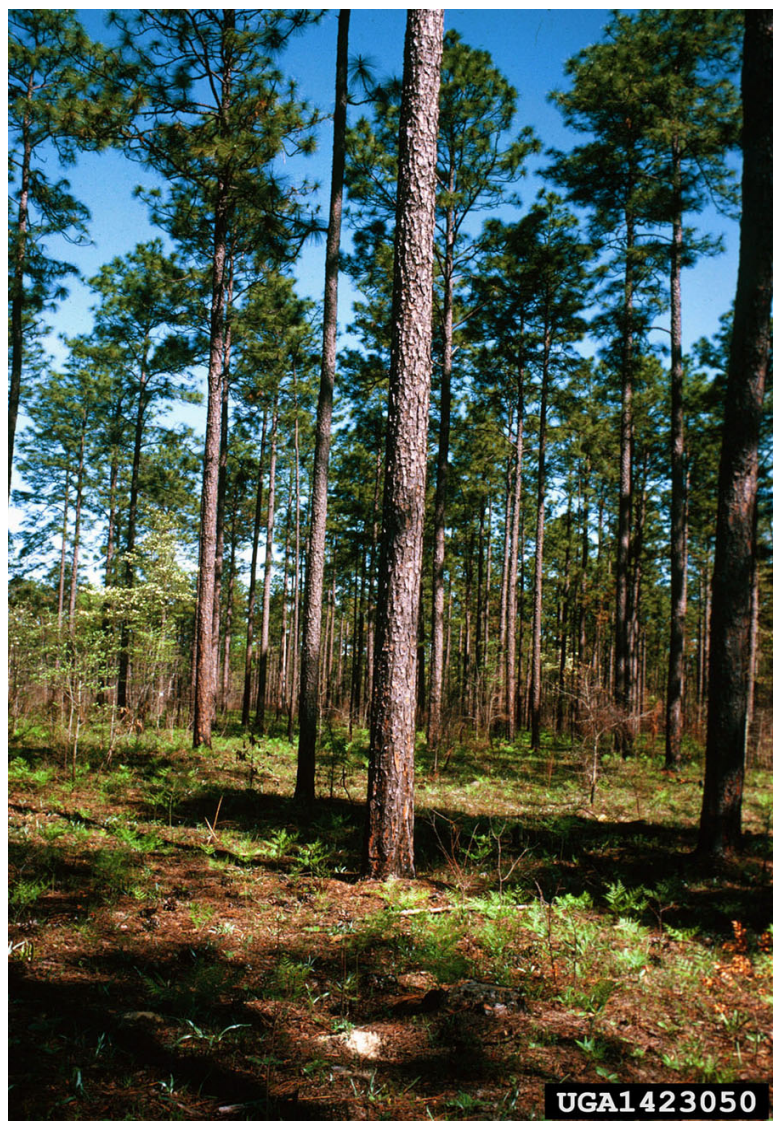

Figure 3.b Credits: William D. Boyer, USDA Forest Service, www.forestryimages.org

wildfire hazard than the flammability of any individual plant. To discuss how plant arrangement influences the overall flammability of a landscape, it is useful to first discuss general differences between broad categories of plants. Grasses, shrubs, and trees have different characteristics that influence ignition and fire spread during wildfires. Each plant type is discussed in the context of their arrangement above the ground because most advancing wildfires spread horizontally through fuels that lie on or within a few feet of the ground.

- Grasses that are dead or drought-stressed ignite rapidly and burn fast due to their thin leaves and position at ground level. In addition, living grass dries out quicker than shrubs and trees during extended periods of dry weather, which is when most wildfires occur. However, a healthy, well-hydrated, green lawn will generally not carry a fire.

- Shrubs have most of their leaves less than six feet from the ground and, therefore, are susceptible to ignition from fires spreading at ground level. The

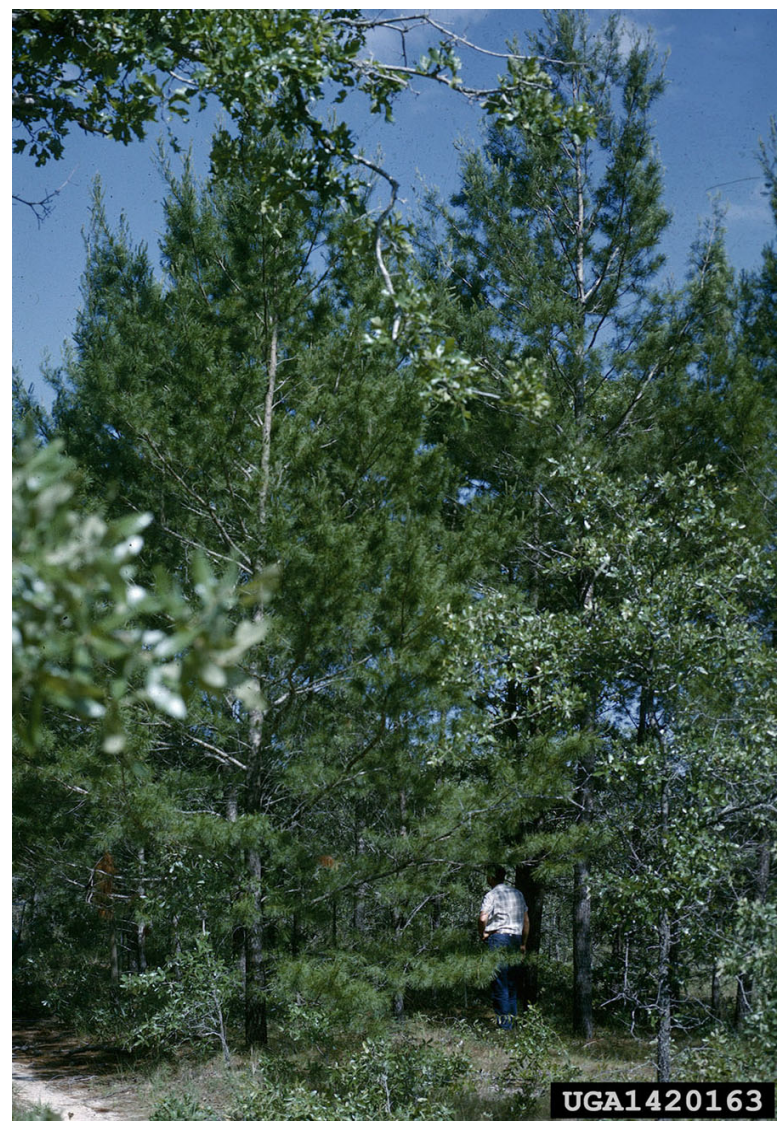

Figure 3.c Credits: William D. Boyer, USDA Forest Service, www.forestryimages.org

Figure 3. Many southern pines, such as longleaf pine (b), are good self-pruners, and their lower trunks are devoid of any branches. Sand pines (c), which do not self-prune, often have branches close to the ground that make them more likely to burn during a wildfire.

abundance of leaves on many shrubs contributes to their overall flammability. In addition, many shrubs have a tendency to grow in dense groups or thickets, which increases their flammability at the landscape scale. For example, gallberry (Ilex glabra) is a native shrub of the southern USA that generally has sparse leaves and branches, characteristics that usually indicate low flammability; however, it occurs naturally in dense groups that are highly flammable. In fact, one of the most flammable naturally occurring groups of plants in the southern USA is the gallberry/saw palmetto shrub layer common to southern pine forests.

- Trees in the forest usually have most of their branches and leaves high above the ground; therefore, a ground-level fire will not easily ignite them unless plants of intermediate height are present to carry the 
flames from the ground to the tree tops. This generalization does not always hold true for isolated trees in open, bright areas, such as grasslands or lawns, which may have branches closer to the ground in response to the abundant light.

Height (or vertical arrangement) is an important characteristic of these plant categories that influences their potential for ignition during a wildfire, and the proximity of a plant (or plant groups) to other plants (horizontal arrangement) directly influences the spread of fire across the landscape. In general, the flammability of a landscape increases with greater connectivity or continuity of fuels (primarily leaves and small branches), both vertically and horizontally. Therefore, the primary objective when landscaping for fire safety is:

- Vertical and horizontal separation. Shrubs, vines, and small trees of intermediate height can act as ladders carrying the flames from the ground to the treetops; such plants are called ladder fuels (Figure 4). A firewise landscape has vertical and horizontal separation between all major fuel sources within the area of defensible space. To maintain vertical separation, all ladder fuels should be cleared from this area, and the lower branches on trees should be pruned up to 10 feet from the ground. Horizontally, groups of plants or landscape beds should be separated by nonflammable areas, such as decorative gravel, stepping stone pathways, bare ground, or a well-maintained, healthy lawn. Mulching can also be used in and around landscape beds, but because the flammability of different landscape mulches is still unclear, some precautions should be taken. We recommend keeping an area of 2 to 3 feet out from the sides of the house clear of mulches. Mulch from yard debris should not be used in the area of defensible space (within 30 feet of house). Mulches composed of large chunks of wood and bark may maintain moisture for a longer time and ignite slower when exposed to a fire; therefore, they may present less of a fire hazard. Pine straw mulches, which dry out quickly, are highly flammable and should be avoided altogether in a firewise landscape.

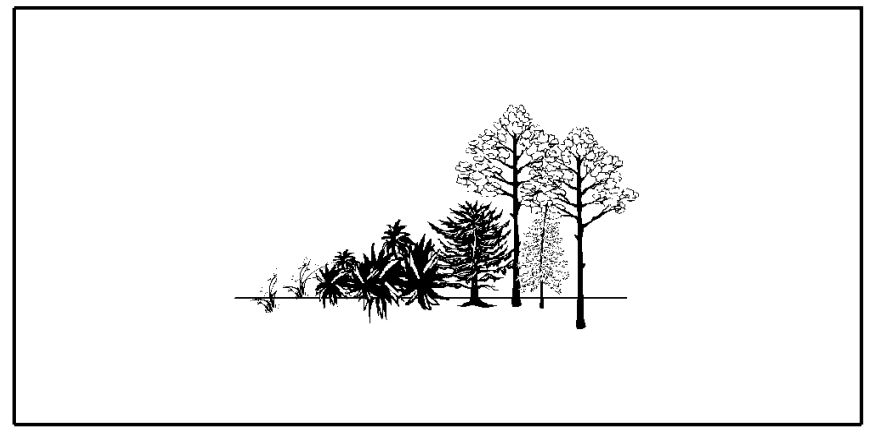

Figure 4. Ladder fuels are medium-sized shrubs or trees that connect fuels at the forest floor to the tops of trees. Credits: Cotton K. Randall, University of Florida

\section{Routine Maintenance is Essential!}

Once the plants are selected and the landscape design is created, routine maintenance is required to preserve firewise properties. Routine maintenance includes timely pruning, irrigation, and the removal of dead leaves, branches, and dead annual herbaceous plants. Shrubs and trees should be pruned to maintain vertical and horizontal separation between leaves and branches. Water is important to maintaining healthy plants; homeowners who live in regions that experience periodic drought should avoid drought-sensitive plants in their landscaping. Dead plant materials removed during routine maintenance can be mulched or composted and used in the landscape to keep nutrients on-site (beyond area of defensible space). By avoiding plants that are fast growing, particularly those that spread quickly, homeowners can reduce the frequency of required maintenance practices. Vines are often fast growing and should be avoided.

\section{Summary}

The most important characteristics of firewise plants are:

- High moisture content. The moisture content of leaves and branches is the single most important factor influencing the flammability of individual plants.

- Broad and thick leaves. Thin leaves or needles tend to dry out quickly and ignite easily.

- Low chemical content. The presence of oils or other chemicals in the leaves and branches can increase flammability. 
- Open and loose branching patterns.

- Deciduousness. Deciduous plants are generally less flammable than evergreens.

- Low amounts of dead materials. The accumulation of dead leaves and branches on plants can increase flammability.

The following southern landscape plants are examples of species that do not meet some of the preceding criteria and are thought to be highly flammable. These plants should be avoided in the area of defensible space around homes that are located in high wildfire risk areas. Beyond the defensible space, individual plants of these species can be maintained, but they should be isolated from other plants and well pruned - maintain vertical and horizontal separation. The key characteristics that contribute to their flammability are listed for each plant.

- Saw palmetto (Serenoa repens) - accumulate dead leaves (fronds); dense, flammable leaves that are close to ground; evergreen.

- Juniper (Juniperus spp.) - small needle-like leaves, evergreen, resins in leaves and branches, often contain dead branches if not pruned.

- Mountain laurel (Kalmia latifolia) - dense leaves and branches close to ground (in younger specimens), evergreen; **Older specimens, which may develop a tree form, with open sparse branching, may be less flammable.

To maintain a firewise landscape, the following routine maintenance practices must be conducted within the area of defensible space:

- Maintain vertical and horizontal separation between groups or islands of landscape plants.

- Prune shrubs and trees periodically to reduce fuel volume, to maintain healthier plants, and to prevent development of ladder fuels.

- Remove dead leaves and branches from standing vegetation and from the ground.
- Remove dead annual plants.

- Water plants adequately to maintain healthy plants and prevent drought stress. If you live in an area where extended dry seasons or droughts are common, consider creating a low water-use landscape with drought-tolerant plants (see publications on waterwise landscaping or xeriscaping: http://www.sjrwmd.com/programs/outreach/ conservation/landscape).

\section{References}

Bond, W. and van Wilgen, B. 1996. Fire and Plants. Chapman and Hall, New York.

Dennis, F.C. 1999. Fire-resistant Landscaping. Colorado State University Cooperative Extension Publication 6.303.

Dennis, F.C. 1999. Firewise Plant Materials. Colorado State University Cooperative Extension Publication 6.305.

Gilmer, M. 1996. Landscaping in the I-zone. Pp. 194-203 in R. Slaughter (ed.), California's I-zone. State of California.

Monroe, M. and Long, A. 2001. Landscaping in Florida with Fire in Mind. University of Florida, Institute of Food and Agricultural Sciences Extension Publication FOR 71, http://edis.ifas.ufl.edu/FR076.

\section{Other Publications in the Fire in the Wildland-Urban Interface Series}

Available at http://edis.ifas.ufl.edu.

Circular 1431: Fire in the Wildland-Urban Interface: Considering Fire in Florida's Ecosystems.

Circular 1432: Fire in the Wildland-Urban Interface: Understanding Fire Behavior. 